\title{
Estabilidade de géis de amido de milho normal, ceroso e com alto teor de amilose adicionados de gomas guar e xantana durante os processos de congelamento e descongelamento
}

\author{
Freeze-thaw stability of normal, waxy and high amylose corn starch gels with added guar and xanthan gums
}

Fernanda Hart WEBER ${ }^{1 \star}$, Fernanda Paula Collares QUEIROZ², Yoon Kil CHANG²

\section{Resumo}

O objetivo do presente trabalho foi estudar os efeitos das gomas guar e xantana sobre a estabilidade dos géis de amido de milho normal, ceroso e com alto teor de amilose submetidos aos processos de congelamento e descongelamento. Os géis desses amidos, com concentração total de sólidos de $10 \%$ e adicionados das gomas $(0,15 ; 0,50 ; 0,85$ e $1 \%)$, foram submetidos a 5 ciclos de congelamento $\left(20\right.$ horas a $\left.-18{ }^{\circ} \mathrm{C}\right)$ e descongelamento ( 4 horas a $25^{\circ} \mathrm{C}$ ), com exceção dos géis com alto teor de amilose, que foram submetidos a apenas 1 ciclo, devido à perda da estrutura de gel. A determinação da sinérese (porcentagem de água liberada) foi realizada pela diferença entre a massa inicial e a massa final das amostras. O gel de amido de milho normal liberou $74,45 \%$ de água, sendo que a adição de $1 \%$ da goma xantana reduziu significativamente a sinérese para $66,43 \%$. A adição de 0,85 e $1 \%$ da goma xantana também reduziu a sinérese dos géis de amido ceroso. $\mathrm{O}$ menor teor de sinérese foi obtido com a utilização de $1 \%$ de goma xantana ao gel de amido de milho com alto teor de amilose, evidenciando a ação crioprotetora desta goma.

Palavras-chave: amido; estabilidade; xantana; guar.

\begin{abstract}
The objective of the present work was to study the effects of guar and xanthan gums on the stability of normal, waxy and high amylose corn starch gels, submitted to freeze-thaw processes. The gels of these starches with a total solids content of $10 \%$ and added gums $(0.15 ; 0.50 ; 0.85$ and $1 \%)$, were submitted to 5 freezing $\left(20\right.$ hours, $\left.-18^{\circ} \mathrm{C}\right)$ and thawing $\left(4\right.$ hours, $\left.25^{\circ} \mathrm{C}\right)$ cycles, with exception of the high amylose gels that were submitted to only 1 cycle. Syneresis (\% water released) was determined by the difference between the initial and final masses of the samples. The normal corn starch gel released $74.45 \%$ water and the addition of $1 \%$ xanthan gum significantly reduced syneresis to $66.43 \%$. The incorporation of 0.85 and $1 \%$ xanthan gum also reduced syneresis of waxy starch gels. The lowest level of syneresis was reached with the use of $1 \%$ xanthan gum in the high amylose corn starch gel, demonstrating the cryo-protective action of the gum.

Keywords: starch; stability; xanthan; guar.
\end{abstract}

\section{Introdução}

A demanda por alimentos prontos tem aumentado consideravelmente nos últimos anos, gerando uma necessidade cada vez maior de disponibilidade de alimentos congelados no mercado. No processo de congelamento, a água presente no alimento transforma-se em cristais de gelo, muitas vezes resultando em stress físico para a matriz estrutural do alimento. Quando o alimento é descongelado para o consumo, a água é facilmente exsudada da matriz, o que provoca uma perda geral da qualidade do alimento, principalmente com relação à perda da textura (RAHMAN apud LEE et al., 2002).

Em muitos alimentos congelados, o amido é usado como agente espessante e exerce a função de melhorar a consistência e a textura, devido às suas propriedades de pasta e capacidade de geleificação (HOLMES; SOLENDER, 1981). Vários autores estudaram a ocorrência de sinérese (liberação de água) devido à retrogradação e mudanças na textura de géis de amido que foram submetidos aos processos de congelamento e descongelamento. Wu e Seib (1990) determinaram que os géis de amido de centeio ceroso e de milho ceroso perderam 55\% de água durante os sete ciclos de congelamento e descongelamento a que foram submetidos. O gel de amido de feijão-de-lima, submetido a três ciclos de congelamento e descongelamento mostrou uma sinérese de $65 \%$, já os géis de amido de milho e batata apresentaram sinérese de 55 e 60\%, respectivamente (HOOVER; MARTIN, 1991). Géis de amido de trigo e arroz submetidos a dois ciclos de congelamento e descongelamento apresentaram sinérese de 37 e $26 \%$, respectivamente (BAKER; RAYARS, 1998).

A sinérese e outras mudanças das propriedades físicas de géis de amido induzidas pelo congelamento e descongelamento podem ser reduzidas pela adição de pequena quantidade de

Recebido para publicação em 27/2/2007

Aceito para publicação em 22/1/2008 (002335)

${ }^{1}$ Universidade Estadual do Rio Grande do Sul-UERGS, Unidade de Três Passos, Rua Cipriano Barata, 47, Bairro Santa Inês, CEP 98600-000, Três Passos - RS, Brasil, E-mail:fernanda-hart@uergs.edu.br

${ }^{2}$ Departamento de Tecnologia de Alimentos, Faculdade de Engenharia de Alimentos, Universidade Estadual de Campinas - Unicamp, Cidade Universitária Zeferino Vaz, CP 621, Campinas - SP, Brasil

${ }^{*}$ A quem a correspondência deve ser enviada 
hidrocolóides. Vários pesquisadores têm se empenhado no estudo para o maior entendimento do mecanismo de crioproteção exercido pelos hidrocolóides (IGOE, 1982; LEE et al., 2002; LIU et al., 2003).

Lee et al. (2002) avaliaram o comportamento de géis de amido de batata doce submetidos a cinco ciclos de congelamento e descongelamento adicionados de várias gomas. A quantidade de goma utilizada foi de 0,3 e 0,6\% e o conteúdo total de sólidos do gel foi de 7\%. Entre as gomas testadas, o alginato de sódio, a goma guar e a goma xantana foram mais efetivas na redução da sinérese. Com a adição de $0,6 \%$ da goma guar observou-se uma sinérese de $33 \%$, metade do valor obtido para o gel de amido controle (sem goma). A goma xantana a $0,3 \%$, no entanto, foi mais efetiva que a goma guar na redução da sinérese. A retrogradação induzida pelo congelamento e descongelamento foi retardada pela presença das gomas, onde o alginato de sódio foi mais efetivo que a goma guar e a goma xantana. Ferrero et al. (1994) também verificaram que a adição da goma xantana ao gel de amido de milho reduziu a retrogradação e, por conseqüência, a sinérese.

No presente estudo foram utilizados dois tipos de hidrocolóides com estruturas químicas distintas, justamente para verificar as diferenças dos efeitos dos mesmos sobre o amido de milho. Utilizou-se a goma guar, um polissacarídeo não iônico, formado por cadeias lineares de unidades de $\mathrm{D}$-manopiranosil ligadas entre si através de ligações $\beta-1,4$ e unidades de D-galactopiranosil, ligadas à cadeia principal de $\mathrm{D}$-manoses por ligações $\alpha-1,6$. E também, a goma xantana, polissacarídeo iônico, constituído de uma cadeia principal de unidades de D-glucose unidas entre si por ligações $\beta$-1,4 com resíduos alternados de $\mathrm{D}$-manose e ácido D-glicurônico, na proporção molar de 2:1, formando a cadeia lateral, possuindo ainda grupos acetil e pirúvico.

Neste trabalho, verificou-se o efeito das gomas guar e xantana na estabilidade dos géis de amido de milho normal ( $27 \%$ de amilose), ceroso ( $98 \%$ amilopectina) e com alto teor de amilose ( $71 \%$ de amilose), submetidos aos processos de congelamento e descongelamento.

\section{Material e métodos}

\subsection{Material}

Os ensaios foram realizados utilizando: i) amido de milho normal - Melojel (M) - (27,8\% de amilose); ii) amido de milho ceroso-Amioca (AP) - (98,2\% de amilopectina); e iii) amido de milho com alto teor de amilose - Hylon VII (AM) - (71,0\% de amilose), fornecidos pela National Starch. Os amidos apresentam as seguintes especificações físico-químicas: cor (branca e levemente amarelada), forma (pó fino), umidade máxima de 14\%, pH (solução a 20\%) de 4,5-7,0.

Os hidrocolóides utilizados foram: goma guar e goma xantana, fornecidos pela Rhodia. A goma xantana (Rhodigel $200^{\circ}$ ) obtida da fermentação pela bactéria Xanthomonas campestris, apresentando as seguintes especificações a $1 \%$ em solução aquosa: viscosidade de 1200 a $1600 \mathrm{cP}$ e pH de 6,0 a 8,0. A goma guar (Higum 55I) obtida do endosperma da semente da planta guar Cyamopsis tetragonolobus, apresentando as seguintes especificações a $1 \%$ em solução aquosa: viscosidade de 5300 a $5500 \mathrm{cP}$ e pH de 5,5 a 6,5 .

\subsection{Preparação dos géis de amido de milho normal e ceroso}

As suspensões de amido de milho normal e ceroso, contendo as gomas $(0,15 ; 0,50 ; 0,85$ e $1 \%)$, com concentração total de sólidos de $10 \%$, foram gelatinizadas em banho-maria a $95{ }^{\circ} \mathrm{C}$ (Dubnoff TE 053, Tecnal, Brasil) durante 15 minutos, sob agitação mecânica (Fisatom, 720, Brasil) a 800 rpm. Os géis ainda quentes foram vertidos em placas de alumínio (com altura de $2 \mathrm{~cm}$ e diâmetro de $8 \mathrm{~cm}$ ), cobertos com filme plástico de PVC (MagiPack) e resfriados à temperatura ambiente por 1 hora. Para comparação dos resultados foram preparados géis dos amidos controle (sem adição de gomas).

\subsection{Preparação do gel de amido com alto teor de amilose}

Para o amido de milho com alto teor de amilose, foi utilizada a mesma concentração total de sólidos e de gomas dos géis de amido normal e ceroso. As suspensões foram gelatinizadas no reator Pressure Reaction Apparatus $\mathrm{n}^{\circ} 4501$ (Parr Instrument Company, USA), sob pressão de $55 \mathrm{psi}$, à temperatura de $150^{\circ} \mathrm{C}$, devido à necessidade de temperatura elevada para a gelatinização deste tipo de amido. Após a preparação dos géis, estes foram colocados em placas de alumínio seguindo o procedimento descrito no item 2.2.

\subsection{Metodologia de determinação da sinérese dos géis submetidos a ciclos de congelamento e descongelamento}

Os géis preparados com o amido de milho normal e ceroso, adicionados das gomas foram submetidos a 5 ciclos de congelamento $\left(20\right.$ horas a $-18^{\circ} \mathrm{C}$ ) e descongelamento ( 4 horas a $25^{\circ} \mathrm{C}$ ) segundo metodologia estabelecida por Lee et al. (2002). Os géis de amido com alto teor de amilose contendo as gomas foram submetidos apenas a um ciclo de congelamento e descongelamento, devido à perda da estrutura de gel, o que impossibilitou a realização de outros ciclos. A determinação da sinérese (porcentagem de água liberada) foi realizada pela diferença entre a massa inicial e a massa final das amostras. A técnica consiste em transferir o gel da placa de alumínio para um papel de filtro Whatmann no 41 sobre um kitassato e proceder à filtragem a vácuo por 10 minutos. Sobre a amostra foi colocado um peso de $1 \mathrm{~kg}$ para acelerar a saída da água. As determinações de sinérese foram realizadas em triplicata.

\subsection{Análise estatística}

Os resultados das determinações de sinérese foram analisados através do emprego de análise de variância (ANOVA), e nos modelos significativos as médias foram comparadas entre si pelo teste de Tukey a 5\% de significância, com o auxílio do programa estatístico SAS ${ }^{\circledast}$ Institute.

\section{Resultados e discussão}

Na Figura 1, são apresentados os valores de sinérese obtidos para os géis de amido de milho normal adicionados de goma guar em diversas concentrações, submetidos a cinco ciclos de 
congelamento e descongelamento. Nas condições experimentais utilizadas, o gel de amido de milho normal sem goma liberou $74,45 \%$ de água depois de ser submetido aos cinco ciclos de congelamento e descongelamento. A adição de 0,50 e $0,85 \%$ de goma guar diminuiu significativamente a sinérese dos géis de amido de milho normal no $1^{\circ}$ ciclo de congelamento e descongelamento, porém este comportamento não foi verificado nos ciclos seguintes, onde a adição da goma em todas as concentrações testadas não mostrou diferença significativa no valor de sinérese em relação ao controle (sem goma). Lee et al. (2002) verificaram efeito adverso nas gomas curdlana, gelana e carragena na estabilidade de géis de amido de batata doce, pois essas gomas aumentaram a sinérese dos géis em 14 e 16; e 1,40 e $15,28 \%$, respectivamente.

Pode-se verificar, pelo gráfico da Figura 2, que a goma xantana foi mais eficiente na redução da sinérese do gel de amido normal do que a goma guar (Figura 1). Observou-se uma diminuição significativa da sinérese com o uso de $1 \%$ desta goma nos ciclos 1, 3, 4 e 5 . A utilização de 0,85\% de goma estabilizou o gel no $1^{\circ}$ ciclo, perdendo sua ação estabilizadora nos demais.

Lee et al. (2002) também verificaram que a goma xantana promoveu uma redução maior da sinérese de géis de amido de batata doce, quando comparada à goma guar e ao alginato de sódio. Ferrero et al. (1993) determinaram que a goma xantana diminuiu a sinérese de pastas de farinha de trigo e de géis de amido de milho. Os autores descobriram que a goma xantana diminuiu os efeitos adversos do congelamento, impedindo a formação de uma estrutura esponjosa, resultante da retrogradação da amilose. As moléculas de amilose que foram lixiviadas dos grânulos no processo de gelatinização ficam expostas e podem estabelecer novas ligações moleculares, que no caso são estabelecidas com a goma xantana. Este fato reduz a possibilidade de associações amilose-amilose, que são as principais ligações envolvidas no processo de retrogradação, pois quando essas mo-

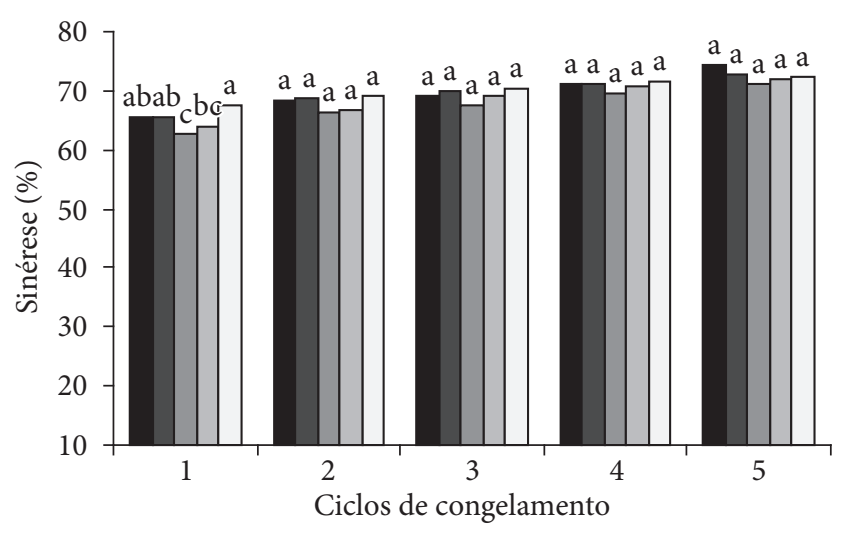

Padrão $\square 0,15 \%$ GG $\square 0,50 \%$ GG $\square 0,85 \%$ GG $\square 1 \%$ GG

Figura 1. Estabilidade de géis de amido de milho normal adicionados de 0,$15 ; 0,50 ; 0,85$ e $1 \%$ de goma guar (GG); ${ }^{\star}$ Letras iguais no mesmo ciclo identificam valores que não diferem a $5 \%$ de significância pelo teste de Tukey. léculas se reassociam ocorre a expulsão da água intramolecular do gel dando origem à sinérese. Não foi verificado pelos autores, efeito da goma xantana na retrogradação da amilopectina.

Lo e Ramsden (2000) reportaram resultados similares e concordaram com essa teoria. Estes pesquisadores chegaram à conclusão de que a goma xantana aumentou a estabilidade de géis de amido de arroz submetidos a ciclos contínuos de congelamento e descongelamento, porém o efeito sobre géis de amido de trigo e de milho foi mínimo. A diferença foi atribuída à baixa quantidade de amilose presente no amido de arroz em relação ao amido de trigo e milho, portanto qualquer alteração na amilose presente no grânulo de amido resultou em grandes alterações na retrogradação do amido de arroz. Eles também concordaram que a goma xantana reage de alguma maneira impedindo as ligações amilose-amilose. Challen (1993) também enfatizou a excepcional habilidade que a goma xantana possui de interagir com as cadeias do amido em relação às outras gomas como, por exemplo, as gomas guar e locusta/ jataí. As propriedades estabilizadoras da goma xantana ocorrem devido à capacidade que esta goma tem de penetrar na rede do gel congelado e estabelecer ligações com as cadeias de amido (SLADE; LEVINE, 1986).

Sudhakar et al. (1996) também determinaram que a maior estabilidade aos processos de congelamento e descongelamento dos amidos adicionados de gomas foi devido à interação entre os hidrocolóides e a amilose, resultando em diminuição da retrogradação e, conseqüentemente, da sinérese. Os mesmos pesquisadores avaliaram o teor de sinérese de géis de amido de milho normal adicionados das gomas guar e goma locusta/ jataí e concluíram que a adição de $0,2 \%$ dessas gomas diminuiu a sinérese de 60,3\% (amido sem goma) para 37,6 e 35,3\%, respectivamente. No presente trabalho, a redução da sinérese do gel de amido normal foi de 74,45\% (controle) para $66,43 \%$ com a adição de $1 \%$ da goma xantana.

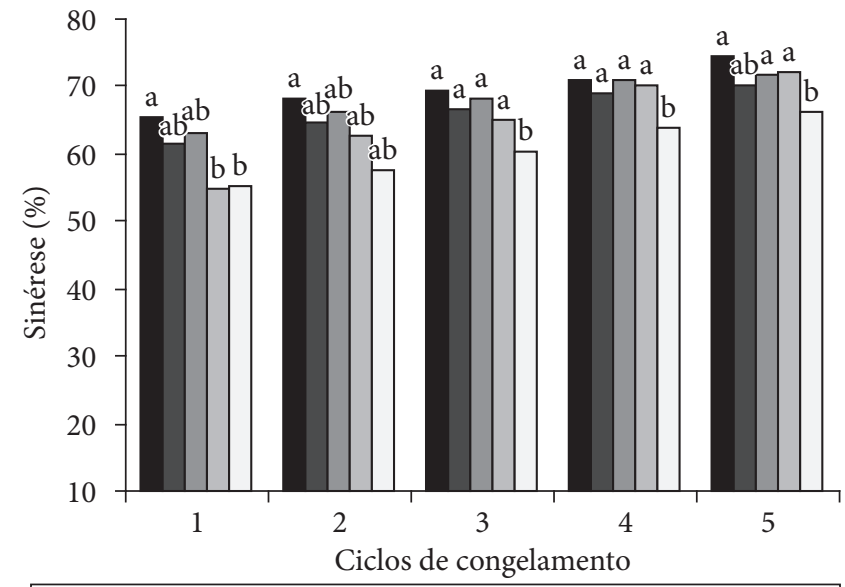

Padrão $\square 0,15 \%$ GX $\square 0,50 \%$ GX $\square 0,85 \%$ GX $\square 1 \%$ GX

Figura 2. Estabilidade de géis de amido de milho normal adicionados de 0,$15 ; 0,50 ; 0,85$ e $1 \%$ de goma xantana (GX); e ${ }^{\star}$ Letras iguais no mesmo ciclo identificam valores que não diferem a $5 \%$ de significância pelo teste de Tukey. 
Sudhakar et al. (1992) verificaram que os géis de amido de milho adicionados de carboximetilcelulose (CMC) apresentaram uma estabilidade maior ao congelamento e descongelamento, ou seja, uma sinérese menor se comparados ao gel controle (sem goma). O aumento na estabilidade foi proporcional à quantidade adicionada, que variou de 0,25 a $1 \%$.

Os géis de amido de milho ceroso apresentaram sinérese inferior (69,55\%) aos géis de amido de milho normal (74,45\%). Isto ocorreu possivelmente porque a retrogradação das cadeias de amilopectina, que tem sua estrutura ramificada, é menor e mais lenta, devido à dificuldade que as moléculas possuem de se rearranjarem. Sudhakar et al. (1992) também verificaram uma estabilidade maior dos géis de amido de amaranto, que são formados praticamente pela molécula de amilopectina, quando comparados aos géis de amido de milho normal.

No primeiro ciclo de congelamento e descongelamento, os valores de sinérese dos géis de amido ceroso foram baixos, ficando na faixa de $7,66 \%$ para o padrão e $4 \%$ para o gel com $1 \%$ da goma guar. A adição de $0,5 \%$ da goma guar diminuiu significativamente a sinérese. A partir do segundo ciclo, ocorreu uma liberação maior de água acima de $40 \%$. A goma guar estabilizou o gel no $1^{\circ}$ ciclo, não afetando a estabilidade do gel nos demais ciclos em todas as concentrações usadas, pois não se detectou diferença significativa entre os géis com a goma e o controle (Figura 3 ).

A goma xantana atuou na estabilidade dos géis de amido de milho ceroso, apresentando diminuição significativa da sinérese nos ciclos 1 e 5 . No ciclo 2, a redução significativa ocorreu com $0,15 \%$ de goma, e nos ciclos 3 e 4 não houve redução. No primeiro ciclo, a sinérese foi reduzida significativamente, onde de 0,15 a $0,85 \%$ apresentou a mesma redução e a $1 \%$ houve a maior redução da sinérese (Figura 4).

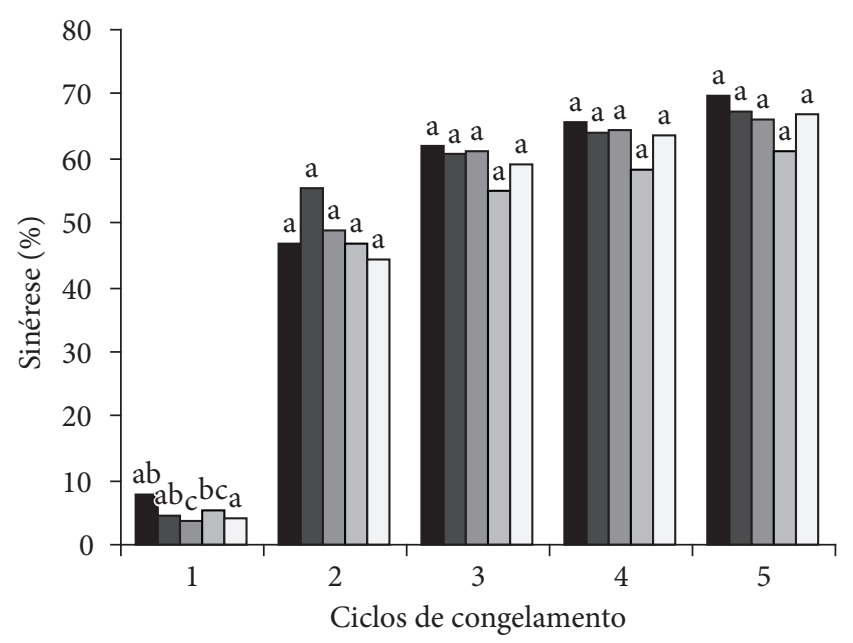

— Padrão $\square$ 0,15\% GG $\square 0,50 \%$ GG $\square 0,85 \%$ GG $\square$ 1\% GG

Figura 3. Estabilidade de géis de amido de milho ceroso adicionados de 0,$15 ; 0,50 ; 0,85$ e $1 \%$ de goma guar (GG); ${ }^{\star}$ Letras iguais no mesmo ciclo identificam valores que não diferem a $5 \%$ de significância pelo teste de Tukey.
O gel de amido de milho com alto teor de amilose sem goma apresentou $62,72 \%$ de sinérese no ciclo de congelamento e descongelamento. Esse valor foi diminuído com a adição das gomas guar e xantana nas concentrações de 0,15 a $1 \%$. Pode-se verificar a ação crioprotetora das gomas, principalmente da xantana, que reduziu a sinérese em $15,27 \%$ na concentração de $1 \%$ (Figura 5).

Liu et al. (2003) também concluíram que a mucilagem de mostarda amarela diminuiu a sinérese dos géis de amido de arroz e de trigo e atribuíram essa diminuição às prováveis interações entre a molécula de amilose e a goma. Outros autores (FERRERO et al., 1994; SUDHAKAR et al., 1992; 1996) obtiveram resultados similares sustentando a teoria proposta

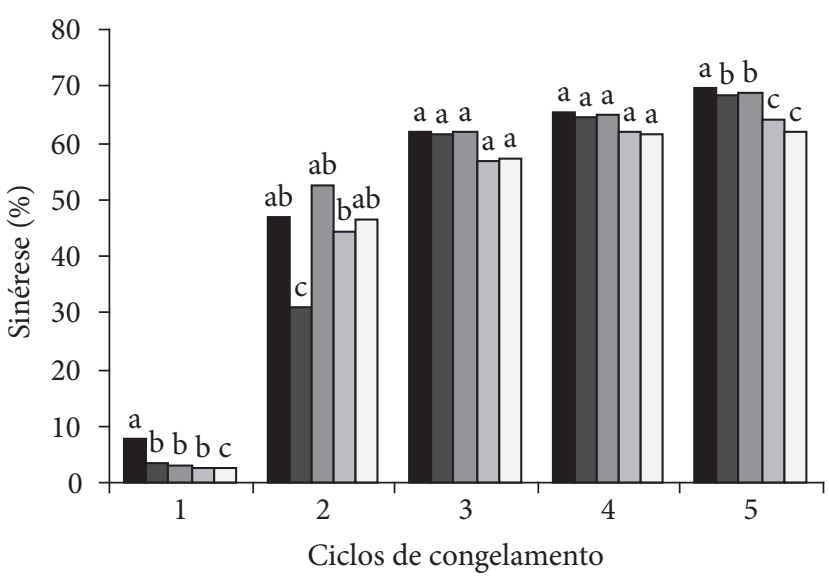

Padrão $\square 0,15 \%$ GX $\square 0,50 \%$ GX $\square 0,85 \%$ GX $\square 1 \%$ GX

Figura 4. Estabilidade de géis de amido de milho ceroso adicionados de 0,$15 ; 0,50 ; 0,85$ e $1 \%$ de goma xantana (GX); e ${ }^{\star}$ Letras iguais no mesmo ciclo identificam valores que não diferem a 5\% de significância pelo teste de Tukey.

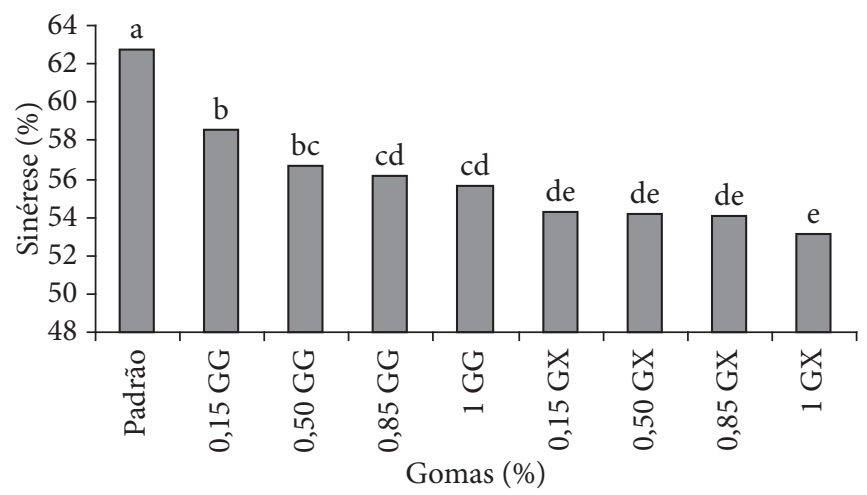

Figura 5. Estabilidade de géis de amido de milho com alto teor de amilose adicionados das gomas guar e xantana submetidos a um ciclo de congelamento e descongelamento. Em que: GG = goma guar e GX = goma xantana; $e^{\star}$ Letras iguais identificam valores que não diferem a 5\% de significância pelo teste de Tukey. 
por Christianson et al. (1981). Lee et al. (2002) propuseram que os efeitos estabilizadores promovidos pelos hidrocolóides na estrutura do gel de amido resultam de interações com a água e com a amilose do amido na mistura.

\section{Conclusões}

O gel de amido de milho normal liberou 74,45\% de água. $A$ adição de 0,50 e 0,85\% de goma guar diminuiu significativamente a sinérese destes géis no $1^{\circ}$ ciclo de congelamento e descongelamento, porém este comportamento não foi verificado nos ciclos seguintes. A adição de $1 \%$ da goma xantana diminuiu significativamente a sinérese do gel nos ciclos 1, 3, 4 e 5 .

O gel de amido de milho ceroso apresentou sinérese de $69,55 \%$. A goma guar, neste caso na concentração de $0,5 \%$, apresentou efeito similar ao observado para o amido normal. A goma xantana estabilizou os géis de amido de milho ceroso nos ciclos 1 e 5 .

O gel de amido de milho com alto teor de amilose apresentou $62,72 \%$ de sinérese. O menor teor de sinérese foi obtido com o uso de $1 \%$ da goma xantana, evidenciando sua ação crioprotetora que reduziu a sinérese dos géis em 15,27\%.

\section{Agradecimentos}

Agradecemos às empresas National Starch e Rhodia pela doação, respectivamente, dos amidos e das gomas. Ao CNPq pela concessão da bolsa de Doutorado e ao FAEP pelo auxílio financeiro ao projeto.

\section{Referências bibliográficas}

BAKER, L. A.; RAYARS, P. Freeze-thaw stability of amaranth starch and the effects of salt and sugars. Cereal Chemistry, Saint Paul, v. 75, p. 301-307, 1998.

CHALLEN, I. A. Xanthan gum: a multifunctional stabilizer for food products. In: NISHINARI, K.; DOI, E. Food Hydrocolloids. New York: Plenum Press, 1993. p. 135-140.

CHRISTIANSON D. D. et al. Gelatinization of wheat starch as modified by xanthan gum, guar gum and cellulose gum. Cereal Chemistry, Saint Paul, v. 58, n. 6, p. 513-517, 1981.
FERRERO, C.; MARTINO, M. N.; ZARITSKY, N. E. Corn starchxanthan gum iteraction and its effect on the stability during storage of frozen gelatinized suspensions. Starch/Starke, Stuttgart, v. 46, p. 300-308, 1994.

. Stability of frozen starch pastes. Effect of freezing, storage and xanthan gum addition. Journal of Food Processing and Preservation, v. 28, p. 350-356, 1993.

HOLMES, Z. A.; SOLENDER, A. Macrostructure of selected raw starches and selected heated starch dispersion. Journal of the American Dietetic Association, v. 78, p. 153-160, 1981.

HOOVER, R. S. C.; MARTIN, A. M. Isolation and characterization of lima bean (Phaselus lunatus) starch. Journal of Food Biochemistry, v. 15, p. 117-136, 1991.

IGOE, R. S. Hydrocolloid interactions useful in food systems. Food Technology, v. 4, p. 72-74, 1982.

LEE, M. H. et al. Freeze-thaw stabilization of sweet potato starch gel by polysaccharide gums. Food Hydrocolloids, v. 16, p. 345-352, 2002.

LIU, H.; ESKIN, N. A. M.; CUI, S. W. Interaction of wheat and rice starches with yellow mustard mucilage. Food Hydrocolloids, v. 17, p. 863-869, 2003.

LO, C. T.; RAMSDEN, L. Effects of xanthan and galactomannan on the freeze/thaw properties of starch gels. Nahrung, v. 44, p. 211-214, 2000.

RAHMAN, M. S. Food Preservation by freezing. In: LEE, M. H. et al. Freeze-thaw stabilization of sweet potato starch gel by polysaccharide gums. Food Hydrocolloids, v. 16, p. 345-352, 2002.

SLADE, L.; LEVINE, H. A polymer physicochemical approach to the study of commercial starch hydrolysis products (SHPs). Carbohydrate Polymers, v. 6, p. 213-244, 1986.

SUDHAKAR V.; SINGHAL R. S.; KULKARNI, P. R. Starchgalactomannan interactions: functionality and rheological aspects. Food Chemistry, v. 55, n. 3, p. 259-264, 1996.

Starch-gum interactions: formulations and functionality using amaranth/corn starch and CMC. Starch/Starke, Stuttgart, v. 44, n. 10, p. 369-374, 1992.

WU, Y.; SEIB, P. A. Acetylated and hydroxypropilated distarch phosphates from waxy barley: paste properties and freeze-thaw stability. Cereal Chemistry, Saint Paul, v. 67, p. 202-208, 1990. 